\title{
Characteristics and Underlying Mechanisms of Semantic Clustering in Parkinson's Disease
}

\author{
Sun Mi Lee ${ }^{\mathrm{a}}$, Ji Hye Yoon ${ }^{\mathrm{b}}$, Soo Jung Lee \\ ${ }^{a}$ Department of Speech Pathology, Graduate School of Health Sciences, Hallym University, Chuncheon, Korea \\ ${ }^{b}$ Division of Speech Pathology and Audiology, Hallym University, Chuncheon, Korea \\ 'Department of Audiology and Speech-Language Pathology, Daegu Catholic University, Gyeongsan, Korea
}

\author{
Correspondence: Ji Hye Yoon, PhD \\ Division of Speech Pathology and Audiology, \\ Hallym University, 1 Hallimdaehak-gil, Chuncheon \\ 24252, Korea \\ Tel: +82-33-248-2224 \\ Fax: +82-33-256-3420 \\ E-mail: j.yoon@hallym.ac.kr
}

Received: April 20, 2018

Revised: May 12, 2018

Accepted: May 12, 2018

This research was supported by Hallym University Research Fund in 2017 (No. HRF-201712-006)

\begin{abstract}
Objectives: Patients with Parkinson's disease (PD) tend to show impairment in switching, but not clustering, during semantic fluency tasks. When time limits are imposed for completing a fluency task, clustering and switching can be negatively correlated. To better understand the characteristics of clustering, verbal fluency needs to be assessed both with and without time limits. The purpose of this study was to investigate the effect of time limits on clustering performance, and to study characteristics of semantic impairment related to clustering in PD. Methods: We studied 27 PD patients and 32 normal controls (NC). We conducted a semantic fluency task and measured the total number of words, average size of clusters, number of clusters, and number of switches generated in a 1-minute time limit, also making the same measurements without a time limit. Finally, we conducted a semantic knowledge task utilizing spontaneous production, specific guiding questions, and forcedchoice questions. Results: First, when there was no time limit the average size of clusters was significantly smaller in PD than in NC. Second, on the semantic knowledge task, the PD patients scored significantly lower than NC on the specific guiding questions and in total. Lastly, we found significant correlations between the average size of clusters and the scores on the semantic knowledge task in PD. Conclusion: On semantic fluency tasks, time limits for completing a task may affect clustering in PD. Also, impaired clustering in PD may be attributed to impaired retrieval of semantic knowledge rather than a deficit in semantic knowledge itself.
\end{abstract}

Keywords: Parkinson's disease, Semantic fluency task, Clustering, Switching, Semantic know
파킨슨병 환자들은 치매를 동반하지 않은 경우에도 병 진행의 초기 단계에서부터 인지기능 감퇴를 경험하기도 하며(Muslimović, Post, Speelman, \& Schmand, 2005) 특히 전두엽 기능저하를 보이 기 쉽다(Farina et al., 2000; Henry \& Crawford, 2004; Taylor, SaintCyr, \& Lang, 1986). 이러한 원인은 파킨슨병 환자가 흑질의 도파민 생산 문제로 인하여 전두엽과 피질하 영역을 잇는 전전두피질회로 가 손상되며 이로 인하여 운동장애뿐만 아니라 인지기능, 성격, 우 울증에 영향을 미칠 수 있기 때문이다(Colman \& Bastiaanse, 2011; Cummings, 1993; Middleton \& Strick, 2000; Owen, 2004). 대조적 으로 파킨슨병 환자의 측두엽 기능은 비교적 온전하다고 알려져 있다(Randolph, Braun, Goldberg, \& Chase, 1993). 구조적 영상연
구에서도 치매를 동반하지 않은 파킨슨병 환자들에게서 전두엽 위 축은 비교적 일관적으로 나타나지만 측두엽 위축에 관해서는 치매 를 동반한 파킨슨병 환자들과 더 관련이 있다고 보고하였다(Beyer, Janvin, Larsen, \& Aarsland, 2007; Gattellaro et al., 2009).

생성이름대기 과제로 흔히 사용되는 범주유창성 과제를 수행하 기 위해서는 전두엽과 측두엽 기능이 필요한데(Frith, Friston, Liddle, \& Frackowiak, 1991; Klein, Milner, Zatorre, Meyer, \& Evans, 1995), 선행연구에서 이를 반영하는 지표로서 전환과 군집분석이 활용된다. 예를 들면, 전환은 하위범주의 단어를 모두 인출하고 난 후에 또 다른 하위범주로 이동하는 것을 말한다(Troyer, Moscovitch, Winocur, Alexander, \& Stuss, 1998). 고갈된 정보를 대체할 수 있는 
다른 정보를 인출할 때는 유연한 사고적 접근과 사용 전략(Ho et al., 2002)이 필요하며 이는 전두엽의 기능과 연관이 있다(Troyer et al., 1998). 군집은 제시된 범주 내에서 의미적으로 서로 연관된 어 휘들을 전략적으로 모아 산출하는 능력이므로(Auriacombe et al., 1993; Troyer, Moscovitch, Winocur, Leach, \& Freedman, 1998) 의 미정보들이 유기적으로 저장되어 있는 곳으로 알려진(Ho et al., 2002; Robert et al., 1998) 측두엽과 연관이 있다(Troyer, Moscovitch, Winocur, Leach, et al., 1998). 이러한 신경해부학적 관점에 따라 파킨슨병 환자의 경우 측두엽 기능이 유지되기 때문에 범주 유창성 과제에서의 군집능력이 온전한 것으로 단순히 해석하였다 (Auriacombe et al., 1993; Donovan, Siegert, McDowall, \& Abernethy, 1999; Ho et al., 2002; Robert et al., 1998; Troyer, Moscovitch, Winocur, Leach, et al., 1998). 그러나 올바른 군집화를 위해서는 측두엽에 저장된 정보인 어휘-의미지식을 전략적으로 탐색하고 인 출하는 전두엽의 처리과정이 수반된다(Moscovitch, 1994). 따라서 군집능력의 본질을 확인하기 위해서는 수행의 최종 산물인 군집 관련 지표뿐만 아니라 군집과 관련된 일련의 처리과정을 단계적으 로 확인해야 한다.

그뿐만 아니라 범주유창성 과제는 주로 1 분이라는 제한된 짧은 시간 내에 가능한 많은 단어를 산출하는 최대 수행과제이므로 군 집과 전환의 수행력은 서로 영향을 줄 수 있다. 예를 들어, 성인이 평균적으로 1 분동안 20 개의 단어를 산출할 수 있다고 가정할 때, 시작과 동시에 하나의 군집 안에서 10 개의 단어를 산출한다면 남 은 전환의 기회는 10 개가 된다. 반대로 시작과 동시에 전환을 많이 사용하여 서로 다른 범주 안에 14 개의 단어를 산출하면 군집으로 만들 수 있는 단어의 개수는 6개가 된다. 즉, 과제수행의 초반에 어 떠한 전략을 선호하거나 선택하는지에 따라 각 전략의 기회 빈도 가 줄어들 수 있다. 즉, 군집 내에서 인출하는 시간과 전환 시간이 길어질수록 전환 기회 수가 줄어들며, 역으로는 전환의 사용이 많 아질수록 군집을 형성할 기회가 줄어든다. 이와 같은 맥락에서 Mayr (2002)와 Troyer, Moscovitch 그리고 Winocur (1997)는 전환 과 군집 수가 부적상관을 보인 것은 제한된 시간이라는 변수 내에 서 과제를 시행하였기 때문이라고 보고하였다. Choi와 Sung (2014) 은 실어증환자들과 정상인들 간의 군집크기가 유의미하지 않은 이 유를 과제의 제한된 시간 동안 정상군이 실어증 환자들보다 잦은 전환 빈도를 보였기 때문으로 해석하였다. 이러한 변수의 영향을 고려해볼 때, 파킨슨병 환자의 군집능력을 보다 정확히 살펴보기 위해서는 과제수행 시간의 변수를 1 분으로 제한할 것이 아니라 다 각적으로 살펴볼 필요가 있다.

이에, 본 연구에서는, 첫째, 범주유창성 과제를 통해 파킨슨병 환
자의 군집능력을 살펴보되, 과제수행 시간이 군집능력에 영향을 미칠 수 있다는 점에 근거하여 시간 제한이 있는 경우(1분)와 제한 이 없는 경우 각각에서 파킨슨병 환자의 군집능력을 정상군과 비 교하고자 하였다. 둘째, 파킨슨병 환자의 군집능력과 의미지식 간 의 관련성을 파악하기 위하여 단계적 의미지식 과제를 시행함으로 써 파킨슨병 환자의 의미지식 특성을 파악하고자 하였다. 셋째, 파 킨슨병 환자의 의미지식 특성과 군집능력 간에는 어떠한 관련성이 있는지 살펴보고자 하였다.

\section{연구방법}

\section{연구대상}

본 연구는 서울, 인천, 경기, 광주, 부산 지역에 거주하고 있으며 한국어를 모국어로 사용하는 파킨슨병 환자 27 명과 정상인 32 명 을 대상으로 시행되었다. 연구의 모든 절차는 한림대학교 생명윤리 위원회(HIRB-2017-0333)의 승인을 받았다. 환자군 선별은 신경과 전문의 혹은 재활의학과 전문의에게 파킨슨병(Parkinson's disease, PD)으로 진단을 받은 만 40세 이상, 75세 미만의 환자들을 대 상으로 하였다. 대상자들은 파킨슨병 이외에 뇌손상 및 뇌혈관장 애에 관한 병력이 없었으며, 지적장애, 실어증과 같은 중복장애가 없고, 과제수행을 위하여 시각적, 청각적 질환으로 인한 진단 및 수 술을 받지 않는 경우로 한정하였다(Gurd et al., 2000; Sohn, as cited in 2016). 인지능력이 생성이름대기 수행력에 영향을 미칠 수 있다 는 선행연구를 근거로 한국판 간이정신상태 검사(Korean version of Mini-Mental State Examination, K-MMSE)를 실시하고 연령 및 교육년수별 정상규준(Kang, 2006)에 근거하여 정상범주에 해당하 는 자만을 대상으로 하였다. 또한 파킨슨병은 우울증을 않고 있을 확률이 높다고 알려져 있으므로(Hwang, Kim, Kim, \& Hong, 2016) 단축형 노인우울척도(Short form Geriatric Depression Scale, SGDS; $\mathrm{Kee}, 1996$ )도 추가적으로 실시하였다. 정상군은 만 40세 이상의 정 상성인을 선별하기 위해 건강선별설문지(Christensen, Multhaup, Nordstrom, \& Voss, 1991), K-MMSE, SGDS를 실시하여 정상에 포 함되는 경우만을 대상으로 하였다. 두 집단(파킨슨병 환자/정상인) 간 연령, 교육년수, K-MMSE 점수, SGDS 점수 차이를 확인하기 위 하여 독립표본 $t$-검정을 실시한 결과, 연령 $(t=1.458)$, 교육년수 $(t=.127), \mathrm{K}-\mathrm{MMSE}$ 점수 $(t=-.290)$ 는 통계적으로 유의한 차이를 보 이지 않았으나 SGDS 점수 $(t=7.041, p<.001)$ 는 통계적으로 유의한 차이를 보였다. 연구대상자에 대한 구체적인 정보는 다음 Table 1 과 같다. 
Table 1. Participants' demographic information

\begin{tabular}{lrrrc}
\hline Characteristic & \multicolumn{1}{c}{ PD } & Normal & $t$ & $p$-value \\
\hline Age (yr) & $61.48 \pm 7.49$ & $58.50 \pm 8.10$ & 1.458 & .150 \\
Education (yr) & $12.41 \pm 2.74$ & $12.31 \pm 2.96$ & .127 & .899 \\
K-MMSE & $28.04 \pm 1.65$ & $28.16 \pm 1.51$ & -.290 & .773 \\
SGDS & $6.56 \pm 3.87$ & $1.16 \pm 1.82$ & 7.041 & $.000^{* * *}$
\end{tabular}

Values are presented as mean \pm SD.

$\mathrm{PD}=$ Parkinson's disease; K-MMSE = Korean version of Mini-Mental State Examination (Kang, Na, \& Hahn, 1997); SGDS=Short form Geriatric Depression Scale (Kee, 1996).

${ }^{* * *} p<.001$.

\section{연구 과제 및 절차}

범주유창성 과제

범주유창성 과제는 의미적 해당 범주 혹은 음소적 해당 범주 안 에 있는 단어들을 최대한 많이 산출하는 과제이다(Ho et al., 2002; Troyer et al., 1997). 본 연구에서는 학력의 영향이 적으면서 의미적 지식과 관련이 있는 의미적 범주유창성 과제를 시행하였다. 연구자 마다 제한시간을 정하는 차이는 있지만 대다수 연구에서 범주유창 성 과제를 시행할 때 1 분이라는 제한시간을 둔다(Acevedo et al., 2000; Kempler, Teng, Dick, Taussig, \& Davis, 1998; Huff, Corkin, \& Growdon, 1986; Kang, Chin, Na, Lee, \& Park, 2000; Randolph et al., 1993). 그러나 본 연구에서는 최대의 수행을 보기 위해 시간 제한이 없는 경우, 즉, 대상자가 계속적으로 반응을 하며 스스로 중단 의사 를 표시할 때까지 과제를 수행하도록 하였다. 단, 시간 제한이 있는 경우와의 비교를 위하여 선행연구와 같이 1 분 내의 수행시간도 분 석하였다. 범주유창성 과제에서 사용되는 의미적 범주 목록으로는 “동물, 채소, 과일, 음식, 음료, 슈퍼마켓에 있는 물건, 탈것, 연장”등 이 시행되고 있다(Acevedo et al., 2000; Kempler et al., 1998; Randolph et al., 1993; Huff et al., 1986). 이들 중 본 연구에서는 국외 연구 에서도 흔히 사용되는 범주로 비교가 용이하여 한국판 통제단어연 상검사(Kang et al., 2000) 중 범주유창성 과제에서 사용되고 있는 ‘동물'과 ‘가게물건’ 범주를 시행하였다.

\section{의미지식 과제}

특정 대상에 관한 어휘지식, 개념, 의미 관계에 대한 정보들을 포 함한 의미지식을 평가하기 위해 임상에서는 대면이름대기(confrontation naming test), 단어 정의하기(verbal definition), 범주분류과 제(categorization task), 단어짝짓기과제(The Pyramids and Palm Trees Test/The Camel and Cactus Test), 서술하기를 통한 의미지식 과제(description task) 등 다양한 의미지식 과제들이 사용되고 있 다(Cho, 2015; Choi, 2008; Heo, Choi, \& Ahn, 2006; Oh, Choi, \&
Kim, 2010; Seo et al., 2006). 이 중 본 연구에서 사용된 의미지식과 제는 사물에 대하여 구체적인 개념을 정의 혹은 설명하는 과제(description of concrete concepts task; Laatu, Hämäläinen, Revonsuo, Portin, \& Ruutiainen, 1999)로 의미지식 안에 저장된 대상에 대한 개념 혹은 정보들을 자발적으로 산출할 수 있는지를 확인하고 자 발적 산출이 불가할 경우 단계별로 단서를 주는 질문을 통하여 의 미지식의 저장 및 인출능력을 단계별로 살펴보는 과제이다.

과제에 사용된 단어의 선정 시에는 문화적 차이로 인해 기존 연 구의 단어를 그대로 번안하여 사용하기에 무리가 있었으므로 다음 과 같은 기준에 따라 수정 및 보완하여 사용하였다. (1) 한국어 기 본어휘의미빈도사전(Seo, 2014)을 참조하여 보통명사 중 빈도수 100 이상의 고빈도 어휘와 빈도수 50 이하의 저빈도 어휘를 모두 추 출하였다. (2) 동음이의어가 있는 경우에는 제외하였다. (3) Laatu 등(1999)이 제시한 바와 같이 추출된 어휘들은 시각적 참조물이 구 체적으로 존재하여 그리거나 상상할 수 있는 사물로 제한하였다. (4) 분명한 구조와 기능적 특성과 상위범주를 가지고 있는 것으로 선택하였다. 이러한 기준에 따라 고빈도 어휘 8 개와 저빈도 어휘 7 개 총 15 개의 어휘가 최종적으로 선정되었다.

\section{과제 시행 절차}

범주유창성 과제의 경우, 동물 범주를 시행한 이후에 가게물건 범주 산출을 하도록 하였으며, 검사자는 대상자에게 “지금부터 편 안하게 해당 범주에 속하는 단어의 이름들을 떠오르는 만큼 최대 한 많이 산출해보세요”라고 지시한 뒤에 대상자가 스스로 과제 중 단에 대한 의사표시를 하는 경우에 과제를 중지하였다.

의미지식과제의 절차는 단서의 제공 유무에 따라서 (1) 스스로 정의하기, (2) 유도질문에 답하기, (3) 선택질문에 답하기로 이루어 진다. 스스로 정의하기는 ‘펭귄이 무엇입니까?’와 같이 정의를 물은 뒤 자유롭게 가능한 많은 의미지식을 산출하도록 유도한다. 대상 자가 스스로 산출하지 못한 항목에 대해서 '펭귄은 무슨 색입니까?', '펭귄의 발은 몇 개 입니까?', '펭권은 어떠한 종류의 날개를 가지고 있습니까?'와 같은 특정적인 유도질문을 제시하고 응답을 산출하 도록 하였다. 이후에도 산출하지 못한 항목에 대해서 '펭귄은 검정 색/흰색 입니까? 아니면 노란색 입니까?', ‘펭귄은 발이 2개입니까? 4 개입니까?', '펭귄의 날개는 작습니까? 큽니까?'와 같은 선택질문 을 통해 정답을 선택하도록 하였다.

\section{자료 분석기준}

\section{범주유창성과제}

정반응에 대한 인정 기준은 Kang 등(2000)의 연구에 따라 해당 
범주에 속하지 않은 반응이나 고유명사는 제외하였고 파생어는 제 일 첫 반응만 채점하였다. 상위개념어와 하위개념어로 반응한 경우 에는 구체적인 하위개념의 단어를 점수에 포함시키고 상위개념어 단어는 채점에서 제외하였다. 마비말장애로 인한 경미한 조음 왜곡 은 정반응으로 간주하였다(as cited in Kim, 2014). 그 후 Troyer 등 (1997) 및 Kim (2016)의 선행연구에 따라 평균군집크기, 군집수, 전 환수를 산출하였다. 군집은 의미적으로 동일한 하위범주에서 단어 를 연속적으로 산출하는 경우를 말한다. 군집수는 산출 시에 형성 된 군집의 수를 세었다. 연속적인 단어를 산출하지 못하고 하나의 단어만을 산출한 경우 군집크기는 0이며, 두 개 이상의 단어를 연 속적으로 산출한 경우에 군집크기는 1이다(Troyer et al., 1997). 평 균군집크기를 구하기 위하여 각각 군집의 크기를 모두 더한 후 군 집수로 나누었다. 전환수는 하나의 하위범주에서 또 다른 하위범 주로의 이동하는 경우로 하나의 군집에서 다른 군집으로 이동한 경우와 하나의 단어로 이동한 경우도 포함하였다(Kim, 2016). 예 를 들면, '소, 말, 비둘기, 꾀꼬리, 나비, 메뚜기, 하마'라고 산출한 경 우에 군집수는 동물의 하위범주 중 가축(소, 말), 새(비둘기, 꾀꼬 리), 곤충(나비, 메뚜기)으로 3 개이다. 평균군집크기는 각각의 군집 크기를 모두 더하여 3 개이며 이를 군집수 3 으로 나눈 값으로 1 개가 된다. 전환수는 군집에서 군집으로 이동이 2 개, 군집에서 단어로 이동이 1 개로 총 3 개이다. 군집과 전환분석 이외에 양적 분석 수치 로 총 산출단어 수를 확인하였다. 이 때, 모든 수치(총 산출 단어수, 평균군집크기, 전환수, 군집수)는 각 1 분동안 이루어진 동물과 가 게 물건에서 산출된 단어를 합한 수치이다.

\section{의미지식 과제}

의미지식 과제의 스스로 정의하기에 대한 반응을 채점하기 위해 선행연구(Chung \& Lee, 2004; Kim, Kang, \& Yoon, 2015; Rhee, 1991; Sung \& Kim, 2011)의 연구를 참조하여 정의하기에 대한 하위 기준을 구조적 특징과 기능적 특징, 상위어로 분류하였다. 구조적 특징의 경우, 제시된 사물에 대한 색깔, 모양, 맛 등과 같은 사물의 고유한 특징들을 가리키며 기능적 특징은 제시된 사물의 용도, 사 용방법 등과 같은 특징들을 의미한다. 상위어의 경우, 각 항목에 대 한 상위범주에 해당하는 단어를 의미한다. 이러한 기준에 따라, 점 수를 받을 수 있는 항목은 15 개의 상위어, 34 개의 구조적 특징, 25 개의 기능적 특징으로 이루어져 있으며 이를 Appendix 1에 제시하 였다. 각각의 점수는 스스로 정의하기에서 정답일 경우에 3 점, 유도 질문에서 정답일 경우 2 점, 선택질문에서 정답일 경우 1 점, 모두 대 답하지 못하는 경우 0 점으로 산정하며 이를 모두 더한 값을 총점 으로 한다. 각각의 스스로 정의하기, 유도질문, 선택질문 단계에서
산출한 항목당 점수를 부여하였다. 예를 들어, 호랑이에 대하여 자 발적으로 '호랑이는 몸에 줄무늬가 있고 덩치가 크지'라고 말한 경 우, ‘줄무늬가 있다', ‘몸집이 크다' 두가지 항목에 대하여 각각 3점 을 부여하여 6점을 획득한 것으로 간주하였다. 이후 호랑이에 대하 여 산출하지 못한 각각의 특징들을 유도질문에서 제시한 다음 정 반응한 경우 각 항목당 2점을 부여하였고 마지막까지 산출하지 못 한 특징들은 선택질문을 통해 다시 한번 제시하여 정반응 가능한 지 살펴보았다. 마지막에 정반응하는 경우에는 1점, 정반응하지 못 하는 경우에는 0 점으로 하였다. 따라서 유도질문과 선택질문에서 각각 최대 74 개의 질문을 제시할 수 있다. 위에 예시에 사용된 질문 들의 예시는 다음과 같다. 스스로 정의하기에서는 '호랑이는 무엇 인가요? (반응이 없는 경우) 호랑이에 대해서 생각나는 대로 모두 말씀해주세요라고 제시되었으며 이후 산출하지 못한 특징들에 대 하여 유도질문에서는 '호랑이는 무슨 색입니까? 호랑이는 어디에 삽니까?'와 같이 질문이 제시되었다. 이후에도 정반응하지 못하는 경우 '호랑이는 노란색 혹은 주황색입니까? 초록색입니까?, 호랑이 는 몸집이 작습니까? 큽니까?'와 같이 제시되었다. 또한 스스로 정 의하기, 유도질문, 선택질문에 대한 정반응 비율을 산출하였다.

\section{타당도 및 신뢰도}

내용타당도를 확인하기 위하여 언어병리학을 전공하는 대학원 생 3 명과 파킨슨 질환 및 노년층 환자에 대한 5년 이상의 임상경험 이 있는 전문가 1 인에게 내용적절성과 관련해 Likert 5 점 척도로 각 문항에 대하여 평가하도록 하였다. 그 결과, 의미지식 과제의 정반 응 기준으로 삼는 항목들에 대한 적절성을 묻는 모든 문항이 3점 에 해당하는 '보통이다' 이상에 해당되었다.

신뢰도의 경우, 언어병리학을 전공하는 대학원생 1 명에게 검사 절차, 기록방법, 분석방법을 자세히 설명한 후, 전체 수집된 자료의 약 $10 \%$ (6명)를 임의로 선정하여 평가자 간 일치율신뢰도(interrater reliability)로 측정하였다. 그 결과, 범주유창성 과제에 대한 일 치율은 $88.33 \%$, 의미지식 과제에 대한 일치율은 $87.5 \%$ 로 나타났다.

\section{자료의 통계처리}

자료의 통계처리는 SPSS version 21 프로그램을 사용하였다. 먼 저 범주유창성 과제의 수행시간을 시간 제한이 있는 경우(1분 내의 수행력)와 시간 제한이 없는 경우(환자가 스스로 중단한 시점까지 의 수행력)로 나누어 각각의 수행력을 산정하였다. 두 집단 간 군집 능력(평균군집크기, 군집수)과 전환능력(전환수), 총 산출단어수 를 비교하기 위해 SGDS 점수를 공변량으로 하여 반복측정 공분산 분석(repeated measure ANCOVA, RM-ANCOVA)을 실시하였다. 
또한 집단 간 의미지식과제 수행력(총점, 스스로 정의하기 정반응 률, 유도질문 정반응률, 선택질문 정반응률) 비교를 위해서 SGDS 점수를 공변량으로 하여 ANCOVA를 실시하였다. 집단에 따라서 의미지식과제 수행력과 군집능력 사이에 어떠한 상관을 보이는지 살펴보기 위하여 Pearson 상관분석을 실시하였다.

\section{연구결과}

\section{범주유창성 과제 수행력}

\section{과제의 제한 시간에 따른 집단 간 총 산출단어수 비교}

시간에 따른 집단 간 총 산출단어수를 비교하기 위해 SGDS 점 수를 공변량으로 설정하여 RM-ANCOVA를 실시하였다. 그 결과, 집단(2요인: 파킨슨병 환자, 정상군 $\times$ 시간(2요인: 시간 제한 있음, 시간 제한 없음)의 상호작용효과가 유의하지 않았으며 $\left(F_{(1,59)}=.109\right.$, $p=.742)$, 시간에 대한 주효과는 유의하나 $\left(F_{(1,59)}=33.169, p<.001\right)$ 집단에 대한 주효과는 유의하지 않았다 $\left(F_{(1,59)}=.121, p=.729\right)$. 시간 제한 여부에 따라각 집단에서산출한총 단어의 수는 Table 2 와같다.

\section{과제의 제한 시간에 따른 집단 간 군집능력(평균군집크기,}

군집수) 비교

시간에 따른 집단 간 군집능력을 비교하기 위해 SGDS 점수를 공 변량으로 설정하여 RM-ANCOVA를 실시하였다. 첫째, 평균군집 크기에 대해서는 집단(2요인: 파킨슨병 환자, 정상군 $) \times$ 시간 $(2$ 요인 시간 제한 있음, 시간 제한 없음)의 상호작용효과가 유의하였으며 $\left(F_{(1,59)}=9.990, p=.003\right)$, 시간에 대한 주효과는 유의하나 $\left(F_{(1,59)}=7.947\right.$, $p=.007)$, 집단에 대한 주효과는 유의하지 않았다 $\left(F_{(1,59)}=1.263\right.$, $p=.266$ ). 상호작용효과에 대한 사후분석으로서 대응별 비교분석

Table 2. Comparisons of the total number of words, clustering ability, and switching ability between groups

\begin{tabular}{llcc}
\hline & & $\mathrm{PD}(\mathrm{N}=27)$ & $\mathrm{NC}(\mathrm{N}=32)$ \\
\hline Total number of words $^{\mathrm{a}}$ & Time limit & $31.06 \pm 1.93$ & $31.83 \pm 1.73$ \\
& No time limit & $87.01 \pm 13.03$ & $93.83 \pm 11.66$ \\
Average size of $_{\text {clusters }}^{\mathrm{a}, \mathrm{b}}$ & Time limit & $4.73 \pm .35$ & $4.50 \pm .31$ \\
Number of clusters $^{\mathrm{a}}$ & No time limit* & $4.95 \pm .41$ & $6.39 \pm .39$ \\
& Time limit & $6.25 \pm .45$ & $6.44 \pm .41$ \\
& No time limit & $15.37 \pm 1.78$ & $15.37 \pm 1.59$ \\
Number of switches $^{\mathrm{a}}$ & Time limit & $19.26 \pm 1.27$ & $18.25 \pm 1.14$ \\
& No time limit & $45.91 \pm 5.62$ & $45.42 \pm 5.03$ \\
\hline
\end{tabular}

Values are presented as covariate-adjusted mean $\pm \mathrm{SE}$.

$\mathrm{PD}=$ Parkinson's disease: $\mathrm{NC}=$ normal controls.

a Significant main effect of time condition, ${ }^{b}$ significant interaction effect of group by time condition.

${ }^{*}$ A pairwise comparison demonstrated a significant difference between groups.
을 실시한 결과, 시간 제한이 있는 경우에는 두 집단 간 평균군집크 기에 차이가 없었으나 $(p=.655)$, 시간 제한이 없는 경우에는 파킨슨 병 환자군이 정상군에 비해 평균군집크기가 유의하게 적은 것으 로 나타났다 $(p=.033)$ (Figure 1). 둘째, 군집수에 대해서는 집단과 시간의 상호작용 효과 $\left(F_{(1,59)}=.071, p=.790\right)$ 및 집단에 대한 주효과 $\left(F_{(1,59)}=.008, p=.931\right)$ 가 모두 유의하지 않았으며, 시간에 따른 주효 과만 유의하게 나타났다 $\left(F_{(1,59)}=43.750, p<.001\right)$. 시간 제한 여부에 따른 각 집단의 평균군집크기 및 군집수는 Table 2와 같다.

\section{과제의 제한 시간에 따른 집단 간 전환능력(전환수) 비교}

시간에 따른 집단 간 총 전환수를 비교하기 위해 SGDS 점수를 공변량으로 설정하여 RM-ANCOVA를 실시하였다. 그 결과, 집단 (2요인: 파킨슨병 환자, 정상군 $) \times$ 시간 $(2$ 요인: 시간 제한 있음, 시간 제한 없음)의 상호작용 효과가 유의하지 않았으며 $\left(F_{(1,59)}=1.479\right.$, $p=.229)$, 시간에 대한 주효과는 유의하나 $\left(F_{(1,59)}=40.534, p<.001\right)$ 집단에 대한 주효과는 유의하지 않았다 $\left(F_{(1,59)}=.012, p=.913\right)$. 시간 제한 여부에 따른 각 집단에서 사용한 전환수는 Table 2와 같다.

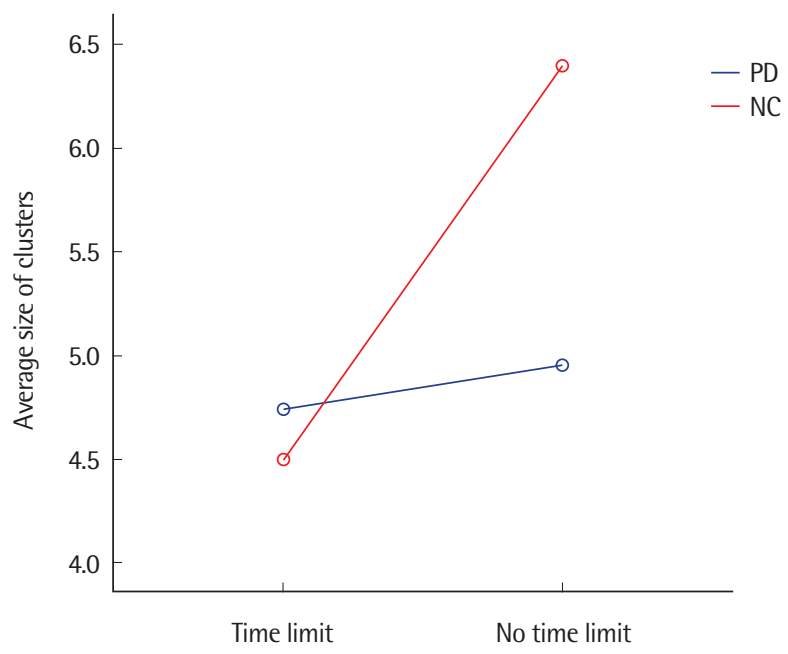

Figure 1. Significant interaction effect of group by time condition for average size of clusters.

$\mathrm{PD}=$ Parkinson's disease; $\mathrm{NC}=$ normal controls.

Table 3. Comparisons of the description task performance between groups

\begin{tabular}{lcccc}
\hline & $\mathrm{PD}(\mathrm{N}=27)$ & $\mathrm{NC}(\mathrm{N}=32)$ & \multicolumn{1}{c}{$F$} & $p$-value \\
\hline Total score & $146.35 \pm 2.93$ & $158.23 \pm 2.63$ & 7.002 & $.011^{*}$ \\
Spontaneous production (\%) & $27.31 \pm 1.99$ & $31.72 \pm 1.78$ & 2.098 & .153 \\
Specific guiding questions (\%) & $57.04 \pm 2.35$ & $71.41 \pm 2.10$ & 15.997 & $<.001^{* * *}$ \\
Forced-choice questions (\%) & $90.96 \pm 1.21$ & $88.78 \pm 1.09$ & 1.380 & .245 \\
\hline
\end{tabular}

Values are presented as covariate-adjusted mean \pm SE.

$\mathrm{PD}=$ Parkinson's disease; $\mathrm{NC}=$ normal controls.

${ }^{*} p<.05,{ }^{* * *} p<.001$. 
Table 4. Correlation coefficient of cluster abilities with semantic memory variables in patients with Parkinson's disease

\begin{tabular}{lcccccc}
\hline & \multicolumn{2}{c}{ Time limit } & & \multicolumn{2}{c}{ No time limit } \\
\cline { 2 - 3 } \cline { 6 - 7 } & $\begin{array}{c}\text { Number of } \\
\text { clusters }\end{array}$ & $\begin{array}{c}\text { Avg size of } \\
\text { clusters }\end{array}$ & & $\begin{array}{c}\text { Number of } \\
\text { clusters }\end{array}$ & $\begin{array}{c}\text { Avg size of } \\
\text { clusters }\end{array}$ \\
\hline Total score & .312 & $.437^{*}$ & & $.608^{* *}$ & $.555^{* *}$ \\
Spontaneous production & .282 & $.385^{*}$ & & $.570^{* *}$ & $.568^{* *}$ \\
Specific guiding questions & .192 & .273 & & $.476^{*}$ & $.406^{* *}$ \\
Forced-choice questions & .099 & .210 & & .116 & .035 \\
\hline
\end{tabular}

${ }^{*} p<.05,{ }^{* *} p<.01$.

\section{의미지식 과제 수행력}

집단 간 의미지식 과제의 수행력을 비교하기 위하여 SGDS 점수 를 공변인으로 한 공분산분석을 실시한 결과, 의미지식 과제의 총점 은 파킨슨병 환자군이 정상군에 비해 유의하게 낮았다 $\left(F_{(1,59)}=\right.$ $7.002, p=.011)$. 집단 간 단서 수준에 따른 정반응률을 비교하기 위 하여 스스로 정의하기, 유도질문, 선택질문의 정반응률을 각각 비 교한 결과, 스스로 정의하기와 선택질문의 정반응률은 집단 간 차 이가 없었으며 $\left(F_{(1,59)}=2.098, p=.153 ; F_{(1,59)}=1.380, p=.245\right.$, respectively), 유도질문의 정반응률에서만 두 집단 간 차이가 나타났다 $\left(F_{(1,59)}=15.997, p<.001\right)($ Table 3$)$.

\section{군집능력과 의미지식 과제 수행력 간 상관관계}

각 집단에서 범주유창성 과제의 군집능력과 의미지식 과제 수행 력 간의 관련성을 알아보기 위하여 군집능력(평균군집크기, 군집 수)과 의미지식 수행력(총점, 스스로 정의하기 정반응률, 유도질문 정반응률, 선택질문 정반응률) 변수들 간의상관관계를 분석하였다.

첫째, 파킨슨병 환자군에서는 시간 제한이 없는 경우에 군집수 와 평균군집크기 모두 의미지식 과제의 총점 $(r=.608, p=.001 ; r=$ $.555, p=.003$, respectively), 스스로 정의하기 정반응률 $(r=.570$, $p=.002 ; r=.568, p=.002$, respectively $)$, 유도질문 정반응률 $(r=.476$, $p=.012 ; r=.406, p=.036$, respectively) 간의 정적상관이 나타났다. 시간 제한이 있는 경우에는 평균군집크기와 총점 $(r=.437, p=.023)$, 스스로 정의하기 정반응률 $(r=.385, p=.047)$ 간 정적상관이 관찰 되었다(Table 4).

둘째, 정상군에서는 시간 제한이 없는 경우, 군집수와총점 $(r=.388$, $p=.028)$ 간에 유의한 정적상관이 있었으나 다른 항목에서는 통계 적으로 유의한 상관이 나타나지 않았다. 시간 제한이 있는 경우, 군 집수 및 평균군집크기와 의미지식 과제 수행력 간에 통계적으로 유의한 상관은 관찰되지 않았다(Table 5).
Table 5. Correlation coefficient of cluster abilities with semantic memory variables in normal adults

\begin{tabular}{lcccccc}
\hline & \multicolumn{2}{c}{ Time limit } & & \multicolumn{2}{c}{ No time limit } \\
\cline { 2 - 3 } \cline { 6 - 7 } & $\begin{array}{c}\text { Number of } \\
\text { clusters }\end{array}$ & $\begin{array}{c}\text { Avg size of } \\
\text { clusters }\end{array}$ & & $\begin{array}{c}\text { Number of } \\
\text { clusters }\end{array}$ & $\begin{array}{c}\text { Avg size of } \\
\text { clusters }\end{array}$ \\
\hline Total score & .334 & .017 & & $.388^{*}$ & .173 \\
Spontaneous production & .267 & .038 & & .308 & .172 \\
Specific guiding questions & .273 & -.056 & & .323 & .019 \\
Forced-choice questions & -.076 & .064 & & -.097 & .089 \\
\hline
\end{tabular}

${ }^{*} p<.05$.

\section{논의 및 결론}

본 연구에서는 범주유창성 과제를 통해 파킨슨병 환자의 군집능 력을 살펴보되, 첫째, 과제 수행 시간이 군집능력에 영향을 미칠 수 있다는 점에 근거하여 시간 제한이 있는 경우(1분)와 제한이 없는 경우의 각각에서 파킨슨병 환자의 군집능력을 정상군과 비교하였 다. 둘째, 파킨슨병 환자의 군집능력과 의미지식 간의 관련성을 파 악하기 위하여 단계적 의미지식 과제를 시행함으로써 파킨슨병 환 자의 의미지식 특성을 파악하였고, 마지막으로, 상관분석을 통해 이러한 의미지식 특성과 군집능력 간에 어떠한 관련성이 있는지 파 악하였다. 본 연구에서 도출된 결과를 토대로 다음의 두 가지 측면 에서 논의점을 제시해보고자 한다.

첫째, 파킨슨병 환자의 군집능력은 과제수행 시간에 영향을 받 으므로 파킨슨병 환자의 군집특성을 보다 면밀하게 파악하기 위해 서는 시간적 변수를 고려할 필요가 있다. 다수의 선행연구들은 범 주유창성 과제에서 나타난 파킨슨병 환자군의 군집능력이 정상군 과 비교하여 차이가 없으며, 이를 근거로 파킨슨병 환자의 군집능 력 및 기저의 의미지식이 보존되어 있음을 주장하였다(Auriacombe et al., 1993; Troyer, Moscovitch, Winocur, Leach, et al., 1998). 단, 이러한 결과들은 과제수행 시간을 일정하게 제한한 상태 에서 도출된 것으로 시간 제한을 두지 않은 상태에서의 군집능력 을 살펴볼 필요가 있다. 본 연구에서는 시간 제한 여부에 따라 파킨 슨병 환자군과 정상군 간의 군집화 양상에 차이가 나타났는데, 즉, 과제수행 시간을 1 분으로 하여 분석하였을 때는 두 집단 간 평균군 집크기에 차이가 없었던 반면, 시간 제한 없이 스스로 중단한 시점 까지의 수행력을 관찰하였을 때는 파킨슨병 환자군이 정상군에 비 해 평균군집크기가 유의하게 적은 것으로 나타났다. 이러한 결과 는 파킨슨병 환자군의 우울증상으로 인하여 시간 제한 없이 과제 를 수행하였을 때 과제수행 시간이 짧아진 것이 아닌지 확인해볼 필요가 있다. 우울 증상에 따른 동기저하나 무기력감 등으로 환자 
군이 정상군에 비해 단어산출을 금방 포기하는 경우가 있다면 이 는 범주유창성 과제의 총 산출단어 개수, 군집, 전환 양상에 큰 영 향요소가 될 수 있기 때문이다. 그러나 동물 범주의 범주유창성 과 제의 경우 정상인 집단에서 평균 3 분 55 초, 환자 집단에서 평균 3 분 05 초 수행시간이 걸렸으며 가게 범주의 범주유창성 과제의 경우 정 상인 집단에서 평균 7 분 11 초, 환자 집단에서 평균 6 분 49 초 수행시 간이 걸렸지만 동물 범주유창성 과제 $(p=.297)$ 와 가게물건 범주유 창성 과제 $(p=.628)$ 수행시간에서 모두 집단 간 유의한 차이가 없었 으므로 이러한 가능성은 배제될 수 있다. 흥미로운 점은 시간 제한 여부에 따른 두 집단 간 군집수 양상에는 차이가 없었다는 점이다. 이는, 의미지식으로부터 특정 범주(예: 동물)에 해당하는 의미적 자질들을 활성화하고 위계화(conceptual hierarchy)하는 것(예: 동 물>새> 까치)에는 어려움이 없으나, 같은 하위범주(예: 새) 내에서 관련성이 있는 어휘목록들을 계속적으로 인출하는 전략이 저하된 것으로 해석할 수 있다. 예컨대, 정상인의 경우에는 특정 군집 안에 서 대표적인 단어를 설정하고 그 단어를 중심으로 다른 관련 단어 들을 산출하는 양상을 보였는데, 대상자가 실제로 반응한 자료를 살펴보면, '까치, 비둘기, 참새, 소, 까치, 앵무새, 메뚜기, 까치, 까마 귀, 공작새' 등으로 산출하는 양상을 확인하였다. 즉, '새'라는 하위 범주 내에서 '까치'라는 대표 단어가 설정되면, 다른 하위범주로 전 환이 일어난 후에도 다시 '까치'라는 대표 단어를 활용하여 하위범 주인 '새'로 돌아와 '날다(fly)'라는 자질을 가진 관련 단어들을 계 속적으로 산출할 수 있게 되는 것이다. 파킨슨병 환자군의 경우에 는 정상인이 사용한 이러한 인출 전략의 결여뿐만 아니라 인지적 억제(cognitive inhibition), 인지적 유연성(cognitive flexibility), 작 업기억(working memory) 등을 포함하는 개념인 전두엽-집행기능 (Diamond, 2013) 측면의 결함이 나타났을 가능성이 높다. 범주유 창성 과제를 잘 수행하기 위해서는 어휘능력과 더불어 집행기능이 요구되는데(Shao, Janse, Visser, \& Meyer, 2014), 즉, 범주에 속하는 새로운 어휘를 지속적으로 산출하기 위해서는 다양한 생각들을 전환할 수 있는 인지적 유연성이 필요하며, 동시에 새로운 어휘가 고갈되기 전까지는 다른 군집으로 너무 쉽게 전환하지 않을 수 있 는 인지적 억제도 필요하다. 또한, 이미 산출한 단어를 기억에 저장 하여 반복 산출하지 않게끔 억제하는 능력도 필요한데, 반복 산출 한 단어는 점수에서 제외되기 때문이다. 본 연구에서 파킨슨병 환 자군은 시간 제한이 없는 조건에서 정상인에 비해 평균군집크기 가 저하되었는데, 이는 파킨슨병 환자군이 특정 한 군집(예: 새) 내 에서도 다양한 개념을 탐색하는 데 필요한 인지적 유연성이 정상인 에 비해 저하될 뿐만 아니라, 인지적 억제 및 작업기억 측면의 저하 로 이미 산출했던 단어를 반복 산출함으로써 평균군집크기가 줄
어들었을 가능성도 있다. 실제로 파킨슨병 환자의 수행을 살펴보면 한 군집 내에서 동일한 단어를 몇 번 반복하는 형태(예: 표범, 하이 에나, 표범, 사자, 호랑이, 표범)를 보이며 군집의 크기가 저하된 경 우가 관찰되었다.

파킨슨병 환자군의 군집특성에 나타난 또 다른 흥미로운 점은 전환수와 군집크기 간에 관련성이 두드러지지 않았다는 점이다. 범주유창성 과제의 특성상 전환의 수가 증가하면 군집크기는 감소 할 수 있다. 하위범주를 바꾸는 빈도가 높을수록(예: 새 $\rightarrow$ 곤충 $\rightarrow$ 포 유류 등), 즉, 전환이 잦을수록, 각 하위범주에 속하는 평균 단어의 수, 즉, 평균군집크기는 줄어들게 된다. 예컨대, 새와 곤충이라는 군 집에서 각각 사마귀, 개미, 거미, 나비, 까마귀, 참새, 기러기, 닭’이라 고 산출한 사람과 사마귀, 까마귀, 개미, 참새, 나비, 기러기, 거미, 닭’이라고 산출한 사람들이 있다고 가정해보자. 전자의 경우 전환 수는 1 회, 평균군집크기는 3 개이며, 후자의 경우 전환수는 7 회, 평 균군집크기는 0 이다. 이렇듯, 전환수와 평균군집크기 간에는 관련 성이 있을 수 있으므로 본 연구에서는 군집능력뿐만 아니라 전환 수를 측정하였으나, 파킨슨병 환자군과 정상군 간 시간 제한 여부 에 따른 평균군집크기에는 차이가 있었지만 두 집단 간 전환수에 는 차이가 나타나지 않았다. 이러한 결과는 파킨슨병 환자군의 전 환능력이 보존되어 있거나, 혹은 본 연구에 포함된 정상군이 전환 전략을 적게 사용하였을 가능성을 시사한다고 생각해볼 수 있으 나, 본 연구 결과만으로는 어느 쪽도 단정할 수 없으며, 파킨슨병 환 자군에서 전환과 군집능력 간의 관련성에 대해서는 추가적인 연구 가 필요하다고 하겠다.

두 번째로 논의할 점은 파킨슨병 환자에서 드러난 군집능력(평 균군집크기)의 저하가 의미지식 자체의 결함이라기보다는 의미정 보의 탐색 및 인출 측면에서의 어려움과 관련된다는 점이다. 범주 유창성 과제를 수행하기 위해서는 제시된 범주에 대한 의미지식과 어휘목록이 온전해야 하며(Auriacombe et al., 1993; Donovan et al., 1999; Troyer, Moscovitch, Winocur, Leach, et al., 1998), 제시된 범주의 하위범주에 접근하여 해당되는 하위의 목록을 전략적으로 활성화(군집)시킬 수 있어야 한다. 그리고 하위범주의 단어를 모두 인출하고 나면 또 다른 하위범주로의 이동(전환)이 원활해야 한다 (Troyer, Moscovitch, Winocur, Alexander, et al., 1998). 그뿐만 아 니라 상기 단계에서 활성화된 의미정보들이 일정한 순서에 따라 적 절하게 인출되어야 한다(Gocer March, E., \& Pattison, 2006; Oh et al., 2010; Sa, Chey, \& Suk, 2011; Troyer, 2000). 선행연구에서는 파 킨슨병 환자의 측두엽 기능이 비교적 잘 유지되며 (Randolph et al., 1993; Rodríguez-Ferreiro et al., 2010), 군집능력이 정상인과 비교 하여 저하되지 않았으므로 파킨슨병 환자의 의미지식 및 어휘목록 
자체는 온전하다고 주장해왔다(Pannu \& Kaszniak, 2005).

본 연구에서는 군집능력의 기저를 이루는 의미지식 특성을 파악 하기 위하여 단계적 의미지식 과제를 실시하였다. 단계적 의미지식 과제란, 대상자의 의미지식 안에 저장된 구체적인 사물에 대한 개 념이나 정보들을 자발적으로 산출하도록 하고, 자발적 산출이 불 가한 경우에 단계별로 단서를 제공하여 의미지식의 저장 결함 혹 은 인출 결함 등을 확인할 수 있는 과제이다. 본 연구에서 의미지식 과제의 총점은 파킨슨병 환자군이 정상군보다 유의하게 낮은 것으 로 나타났다. 단, 총점은 대상자가 스스로 의미정보들을 산출한 점 수와, 대상자의 오반응 여부에 따라 단서 수준을 다르게 제시하여 얻어진 점수들이 모두 합산된 점수로서, 의미지식의 어떠한 측면에 결함이 있는지를 파악하기 위해서는 총점 이외에 각 단계별 수행 력을 파악하는 것이 보다 중요하다고 하겠다. 이에, 단서 수준에 따 른 정반응률을 분석한 결과, 유도질문에서는 파킨슨병 환자군이 정상군에 비해 낮은 수행력을 보였으나, 선택질문에서는 두 집단 간 정반응률에 차이가 없는 것으로 나타났다. 이러한 결과가 도출 된 원인으로 두 질문의 과제가 가진 차별적 특성에 주목할 필요가 있다. 유도질문 과제는 해당 단어가 가진 의미정보인 색깔, 모양, 사 용방법, 범주 등을 묻는 질문을 통해 상위어, 기능적, 구조적 특성 의 산출을 유도한다(예: 펭귄은 무슨 색입니까? 펭귄의 발은 몇 개 입니까? 등). 물론 대상자에게는 자발적인 산출 상황보다 많은 정보 가 단서로서 주어진다. 그러나 유도질문에 반응하기 위해서는 주어 진 정보 안에서 적절한 의미정보를 탐색해야 한다. 의미정보를 탐색 하기 위해서는 인지적 유연성, 유지, 모니터링, 조작하는 인지적 전 략이 필요한데(Costafreda et al., 2006; Martin \& Chao, 2001) 이러 한 전략은 전두엽 기능과 관련이 있다(Mangels, 1997). 배외측 전전 두엽피질회로(dorsal-lateral prefrontal circuite)는 측두엽과 연결되 어 의미지식의 활성화 및 의미정보의 탐색을 중재하는 것과 관련 있으며(Cummings, 1993; Lee et al., 2003), 파킨슨병 환자의 기저핵 손상은 이러한 전전두엽피질회로의 기능부전으로 이어진다(Copland, 2003). 즉, 파킨슨병 환자의 경우, 의미지식 안에서 정보를 탐 색할 때, 과제와 관련된 정보를 유지하고 적절한 정보가 무엇인지 를 모니터링하는 능력에 결함이 생기므로(Farina et al., 2000; Henry \& Crawford, 2004; Muslimović et al., 2005; Taylor et al., 1986) 유도질문 과제에서 어려움을 보이게 되는 것이다(Scimeca \& Badre, 2012). 이에 비해, 선택질문 과제는 두 가지의 구체적 정보를 보기로 제시하고 대상자에게 그 중 하나를 선택하도록 하므로(예: 펭귄은 검정색/흰색입니까 아니면 노란색입니까? 펭귄의 발은 2 개 입니까 아니면 4 개입니까? 등) 유도질문 과제에 비하여 많은 정보를 제공하면서 의미정보에 보다 직접적으로 접근하도록 도와준다. 따
라서 대상자는 저장된 의미지식과의 비교를 통해 주어진 정보에 대 한 정오 판단만을 하면 되므로 의미지식이 보존되어 있기만 한다 면 탐색이나 인출 등의 인지적 처리과정의 부담 없이 과제를 수행 할 수 있는 것이다. 이러한 측면에서 볼 때, 파킨슨병 환자는 의미지 식 자체는 보존되지만 의미정보를 탐색 및 인출하는 것에 어려움이 있으며, 이러한 어려움이 범주유창성 과제에서 군집크기의 저하로 반영된 것으로 해석해 볼 수 있다. 상관분석 결과 역시 이를 뒷받침 하는데, 파킨슨병 환자군에서 군집능력과 의미지식 과제의 총점, 스스로 정의하기 정반응률, 유도질문 정반응률 간에 유의미한 상 관을 확인하였다. 선택질문은 의미지식 자체를 좀 더 반영하는 과 제이나 스스로 정의하기나 유도질문의 경우에는 의미지식과 더불 어 인출능력이 요구되는 과제이다. 따라서 이러한 결과는 파킨슨병 환자군의 군집능력이 의미지식과 관련 있으며, 의미지식 자체보다 는 의미정보를 인출하는 능력과 상관이 있음을 확인할 수 있다. 이 는 파킨슨병 환자의 군집능력 저하가 전두엽-집행기능의 손상에 따른 인출 단계의 결함이라고 보았던 이전 연구결과(Raskin, Sliwinski, \& Borod, 1992)와도 일맥상통한다.

본 연구결과 가운데 특기할만한 점은 파킨슨병 환자군과 정상군 간 의미지식 과제의 스스로 정의하기 수행력에 차이가 없었다는 점 이다. 이러한 결과는 앞서 설명한 파킨슨병 환자군의 전전두엽피질 회로의 기능부전뿐만 아니라 정상군의 노화에 따른 의미정보 인 출능력의 손상을 의심케 한다. 두 집단의 스스로 정의하기 수행력 을 살펴보면, 파킨슨병 환자군은 $27.31 \% \pm 1.99 \%$, 정상군은 $31.72 \%$ $\pm 1.78 \%$ 로 두 집단 모두 10 가지 항목 중 평균 3 가지 항목 정도에서 만 정반응이 가능한 정도로 수행력이 저하되었다. 이는 노화에 따 라 사물을 정의하기 능력이 저하되는 양상이 반영되었을 수 있고 (Kim \& Yoon, 2016), 더불어 기능적, 물리적, 분류적 정의를 적절하 게 분배하여 산출할 수 있는 청년층과 달리 노년층은 기능적, 관계 적 정의하기에 치중되어 있는 특징들(Kim \& Choi, 2012)이 반영된 결과일 수도 있다. 그러나 유도질문에서 두 집단 간에 수행력 차이 가 나타났다는 점은, 정상군의 경우 비록 스스로 정의하기에는 어 려움이 있었다 하더라도 유도질문을 통해 기능적, 물리적, 분류적 측면에서의 의미정보를 산출할 수 있는 단서가 주어지면 이러한 정 보들을 적절하게 인출해낼 수 있는 반면, 파킨슨병 환자군은 이러 한 단서들에도 불구하고 적절한 의미정보들을 탐색하여 인출하는 데 어려움이 있음을 의미한다.

요약하자면, 본 연구는 첫째, 범주유창성 과제수행 시간의 제한 여부가 파킨슨병 환자의 군집능력 평가에 영향을 미칠 수 있으며, 둘째, 파킨슨병 환자의 군집능력 저하는 의미지식과 상관이 있는 데, 이는 의미지식 자체의 결함에 기인한다기보다는 의미정보들을 
적절히 인출하는 단계에서의 결함을 반영한다는 사실을 확인하였 다. 본 연구결과는 임상에서 범주유창성 과제를 통하여 파킨슨병 환자의 군집능력을 평가하고자 할 때 과제수행 시간을 함께 고려해 야 하는 근거를 제공하며, 더불어 파킨슨병 환자의 군집능력 저하 의 기저 양상을 파악하기 위해서는 의미지식 처리과정 전체를 함 께 살펴볼 필요가 있음을 시사한다. 본 연구의 제한점은 다음과 같 다. 파킨슨병 환자의 군집능력의 기저를 확인하기 위해서는 시간적 제약이 없는 자연스러운 상태에서 최대한의 수행력을 측정하는 것 이 우선적인 목표였으며 추가적으로 본 연구결과를 기존 연구결과 와 비교하기 위하여 1 분 내의 수행력을 분석하였다. 그러나 검사 지 시문에 ‘최대한 빨리’라는 제약을 주는 정보가 제공되지 않으므로 피험자가 과제수행 시 시간 제약을 인지하지 않았을 가능성이 있 다. 또한 시간 제약이 있다는 것을 인지하고 있는 경우와 그렇지 않 은 경우에 피험자가 과제를 수행할 때 다른 전략을 사용할 가능성 도 존재한다. 따라서, 추후 연구에서는 과제에 대한 학습효과가 영 향을 미치는 기간을 고려한 상태에서 시간적 제약 정보의 제공 유 무에 따른 수행력을 2 회로 나누어 측정할 필요가 있겠다.

\section{REFERENCES}

Acevedo, A., Loewenstein, D. A., Barker, W. W., Harwood, D. G., Luis, C., Bravo, M., ... \& Duara, R. (2000). Category fluency test: normative data for English-and Spanish-speaking elderly. Journal of the International Neuropsychological Society, 6, 760-769.

Auriacombe, S., Grossman, M., Carvell, S., Gollomp, S., Stern, M. B., \& Hurtig, H. I. (1993). Verbal fluency deficits in Parkinson's disease. Neuropsychology, 7, 182-192.

Beyer, M. K., Janvin, C. C., Larsen, J. P., \& Aarsland, D. (2007). A magnetic resonance imaging study of patients with Parkinson's disease with mild cognitive impairment and dementia using voxel-based morphometry. Journal of Neurology, Neurosurgery \& Psychiatry, 78, 254-259.

Cho, E. (2015). Application of semantic knowledge test for four-to six-year-old children (Master's thesis). Daegu University, Gyeongsan, Korea.

Choi, H. J. (2008). A comparison of the performances of confrontation naming test and verbal fluency task in patients with prodromal Alzheimer's disease and mild Alzheimer's disease. Korean Journal of Speech Sciences, $15,111-118$.

Choi, H. M., \& Sung, J. E. (2014). The relationship between working memory capacity and the abilities of generative naming in persons with aphasia. Journal of Speech-Language, and Hearing Disorders, 23, 23-34.
Christensen, K. J., Multhaup, K. S., Nordstrom, S., \& Voss, K. (1991). A cognitive battery for dementia: development and measurement characteristics. Psychological Assessment: A Journal of Consulting and Clinical Psychology, 3, 168-174.

Chung, Y. C., \& Lee, J. M. (2004). A study of intrinsic and extrinsic semantic features of Korean nouns: focusing on the categories of grains, fruits and vegetables. Korean Journal of Cognitive Science, 15, 43-67.

Colman, K., \& Bastiaanse, R. (2011). Language processing in Parkinson's disease patients without dementia. In J. Dushanova (Ed.), Diagnostics and rehabilitation of Parkinson's disease (pp. 165-185). London: IntechOpen.

Copland, D. (2003). The basal ganglia and semantic engagement: potential insights from semantic priming in individuals with subcortical vascular lesions, Parkinson's disease, and cortical lesions. Journal of the International Neuropsychological Society, 9, 1041-1052.

Costafreda, S. G., Fu, C. H., Lee, L., Everitt, B., Brammer, M. J., \& David, A. S. (2006). A systematic review and quantitative appraisal of fMRI studies of verbal fluency: role of the left inferior frontal gyrus. Human Brain Mapping, 27, 799-810.

Cummings, J. L. (1993). Frontal-subcortical circuits and human behavior. Archives of Neurology, 50, 873-880.

Diamond, A. (2013). Executive functions. Annual Review of Psychology, 64, 135-168.

Donovan, K., Siegert, R., McDowall, J., \& Abernethy, D. (1999). Clustering and switching in verbal fluency in Parkinson's disease. New Zealand Journal of Psychology, 28, 61-66.

Farina, E., Gattellaro, G., Pomati, S., Magni, E., Perretti, A., Cannata, A. P., ... \& Mariani, C. (2000). Researching a differential impairment of frontal functions and explicit memory in early Parkinson's disease. European Journal of Neurology, 7, 259-267.

Frith, C. D., Friston, K. J., Liddle, P. F., \& Frackowiak, R. S. J. (1991). A PET study of word finding. Neuropsychologia, 29, 1137-1148.

Gattellaro, G., Minati, L., Grisoli, M., Mariani, C., Carella, F., Osio, M., ... \& Bruzzone, M. G. (2009). White matter involvement in idiopathic Parkinson disease: a diffusion tensor imaging study. American Journal of Neuroradiology, 30, 1222-1226.

Gocer March, E., \& Pattison, P. (2006). Semantic verbal fluency in Alzheimer's disease: approaches beyond the traditional scoring system. Journal of Clinical and Experimental Neuropsychology, 28, 549-566.

Gurd, J. M. (2000). Verbal fluency deficits in Parkinson's disease: individual differences in underlying cognitive mechanisms. Journal of Neurolinguis- 
tics, $13,47-55$.

Henry, J. D., \& Crawford, J. R. (2004). Verbal fluency deficits in Parkinson's disease: a meta-analysis. Journal of the International Neuropsychological Society, 10, 608-622.

Heo, J., Choi, S., \& Ahn, C. (2006). Development and validation of the Pyramids and Palm Trees Test for semantic memory. Proceedings of the 2006 Korean Psychological Association, 602-603.

Ho, A. K., Sahakian, B. J., Robbins, T. W., Barker, R. A., Rosser, A. E., \& Hodges, J. R. (2002). Verbal fluency in Huntington's disease: a longitudinal analysis of phonemic and semantic clustering and switching. Neuropsychologia, 40, 1277-1284.

Huff, F. J., Corkin, S., \& Growdon, J. H. (1986). Semantic impairment and anomia in Alzheimer's disease. Brain and Language, 28, 235-249.

Hwang, K. J., Kim, E. H., Kim, Y. J., \& Hong, S. B. (2016). Frequency of depression and suicidality in patients with neurological disorders: epilepsy, Parkinson's disease, and ischemic stroke. Journal of the Korean Neurological Association, 34, 193-200.

Kang, Y. (2006). A normative study of the Korean-Mini Mental State Examination (K-MMSE) in the elderly. Korean Journal of Psychology: General, 25, 1-12.

Kang, Y., Chin, J. H., Na, D. L., Lee, J. H., \& Park, J. S. (2000). A normative study of the Korean version of Controlled Oral Word Association Test (COWAT) in the elderly. Korean Journal of Clinical Psychology, 19, 385392.

Kang, Y., Na, D. L., \& Hahn, S. (1997). A validity study on the Korean MiniMental State Examination (K-MMSE) in dementia patients. Journal of the Korean neurological association, 15, 300-308.

Kee, B. S. (1996). A preliminary study for the standardization of geriatric depression scale short form-Korea version. Journal of Korean Neuropsychiatric Association, 35, 298-307.

Kempler, D., Teng, E. L., Dick, M., Taussig, I. M., \& Davis, D. S. (1998). The effects of age, education, and ethnicity on verbal fluency. Journal of the International Neuropsychological Society, 4, 531-538.

Kim, J. (2016). Variables affecting on generative naming of middle-aged and elderly people: working memory, executive function, education level (Master's thesis). Yonsei University, Seoul, Korea.

Kim, J., Kang, Y., \& Yoon, J. H. (2015). Category norms for Korean adults age 55 to 74. Communication Sciences \& Disorders, 20, 559-569.

Kim, M. (2014). Characteristic of error types and generative naming according to clue stimuli in paitents with Broaca's aphasia (Master's theis). Kosin Uni- versity, Busan, Korea.

Kim, S. J., \& Choi, H. (2012). Characteristics of verbal definitions in normal elderly Koreans. Korean Journal of Communication \& Disorders, 17, 107117.

Kim, Y. S., \& Yoon, J. H. (2016). Characteristics of the defining ability of the elderly in nouns, verbs, and adjectives. Communication Sciences \& Disorders, 21, 271-283.

Klein, D., Milner, B., Zatorre, R. J., Meyer, E., \& Evans, A. C. (1995). The neural substrates underlying word generation: a bilingual functional-imaging study. Proceedings of the National Academy of Sciences, 92, 2899-2903.

Laatu, S., Hämäläinen, P., Revonsuo, A., Portin, R., \& Ruutiainen, J. (1999). Semantic memory deficit in multiple sclerosis; impaired understanding of conceptual meanings. Journal of the Neurological Sciences, 162, 152-161.

Lee, S. H., Choi, B. K., Lee, H. S., Lee, H. S., Park, S. W., Chang, H., ... \& Jung, E. T. (2003). A case of extrapontine myelinolysis with both frontal lobe dysfunction and decreased perfusion in SPECT. Journal of the Korean Neurological Association, 21, 195-198.

Mangels, J. A. (1997). Strategic processing and memory for temporal order in patients with frontal lobe lesions. Neuropsychology, 11, 207-221.

Martin, A., \& Chao, L. L. (2001). Semantic memory and the brain: structure and processes. Current Opinion in Neurobiology, 11, 194-201.

Mayr, U. (2002). On the dissociation between clustering and switching in verbal fluency: comment on Troyer, Moscovitch, Winocur, Alexander and Stuss. Neuropsychologia, 40, 562-566.

Middleton, F. A., \& Strick, P. L. (2000). Basal ganglia and cerebellar loops: motor and cognitive circuits. Brain Research Reviews, 31, 236-250.

Moscovitch, M. (1994). Cognitive resources and dual-task interference effects at retrieval in normal people: the role of the frontal lobes and medial temporal cortex. Neuropsychology, 8, 524-534.

Muslimović, D., Post, B., Speelman, J. D., \& Schmand, B. (2005). Cognitive profile of patients with newly diagnosed Parkinson disease. Neurology, 65, 1239-1245.

Oh, H. G., Choi, H., \& Kim, S. (2010). Differences of language impairment related to semantic memory in patients with Alzheimer disease and vascular dementia. Journal of Speech \& Hearing Disorders, 19, 73-84.

Owen, A. M. (2004). Cognitive dysfunction in Parkinson's disease: the role of frontostriatal circuitry. The Neuroscientist, 10, 525-537.

Pannu, J. K., \& Kaszniak, A. W. (2005). Metamemory experiments in neurological populations: a review. Neuropsychology Review, 15, 105-130.

Randolph, C., Braun, A. R., Goldberg, T. E., \& Chase, T. N. (1993). Semantic 
fluency in Alzheimer's, Parkinson's, and Huntington's disease: dissociation of storage and retrieval failures. Neuropsychology, 7, 82-88.

Raskin, S. A., Sliwinski, M., \& Borod, J. C. (1992). Clustering strategies on tasks of verbal fluency in Parkinson's disease. Neuropsychologia, 30, 95-99.

Rhee, K. Y. (1991). Korean category norms: survey on exemplar frequency norm, typicality, and features. Korean Journal of Experimental and Cognitive Psychology, 3, 131-160.

Robert, P. H., Lafont, V., Medecin, I., Berthet, L., Thauby, S., Baudu, C., \& Darcourt, G. U. Y. (1998). Clustering and switching strategies in verbal fluency tasks: comparison between schizophrenics and healthy adults. Journal of the International Neuropsychological Society, 4, 539-546.

Rodríguez-Ferreiro, J., Cuetos, F., Herrera, E., Menéndez, M., \& Ribacoba, R. (2010). Cognitive impairment in Parkinson's disease without dementia. Movement Disorders, 25, 2136-2141.

Sa, S. Y., Chey, J. Y., \& Suk, J. S. (2011). Semantic structure of the elderly Koreans as assessed by category fluency test: effects of literacy and education. Korean Journal of Psychology: General, 30, 227-242.

Scimeca, J. M., \& Badre, D. (2012). Striatal contributions to declarative memory retrieval. Neuron, 75, 380-392.

Seo, E. H., Park, H. H., Lee, D. Y., Choo, I. H., Lee, J. H., Chung, S. H., ... \& Woo, J. I. (2006). A comparison of five scoring methods of clock drawing test for Alzheimer's disease screening. The Korean Journal of Psychopathology, 15, 19-26.

Seo, S. (2014). Dictionary of the usage frequency of basic Korean vocabulary. Seoul: Hankookmunhwasa.

Shao, Z., Janse, E., Visser, K., \& Meyer, A. S. (2014). What do verbal fluency tasks measure? Predictors of verbal fluency performance in older adults. Frontiers in Psychology, 5, 772

Sohn, J. (2016). Characteristics and variables of the generative naming task in Parkinson's disease (Master's thesis). Yonsei University, Seoul, Korea.

Sung, J. E., \& Kim, J. K. (2011). Differential performance on generative naming and typicality rating between young and older adults: a preliminary study to develop a semantic complexity-based naming treatment for persons with neurogenic communication disorders. Journal of Speech \& Hearing Disorders, 20, 31-49.

Taylor, A. E., Saint-Cyr, J. A., \& Lang, A. E. (1986). Frontal lobe dysfunction in Parkinson's disease: the cortical focus of neostriatal outflow. Brain, 109, 845-883.

Troyer, A. K. (2000). Normative data for clustering and switching on verbal fluency tasks. Journal of Clinical and Experimental Neuropsychology, 22, $370-378$.

Troyer, A. K., Moscovitch, M., \& Winocur, G. (1997). Clustering and switching as two components of verbal fluency: evidence from younger and older healthy adults. Neuropsychology, 11, 138-146.

Troyer, A. K., Moscovitch, M., Winocur, G., Alexander, M. P., \& Stuss, D. (1998). Clustering and switching on verbal fluency: the effects of focal frontal-and temporal-lobe lesions. Neuropsychologia, 36, 499-504.

Troyer, A. K., Moscovitch, M., Winocur, G., Leach, L., \& Freedman, M. (1998). Clustering and switching on verbal fluency tests in Alzheimer's and Parkinson's disease. Journal of the International Neuropsychological Society, 4, $137-143$. 
Appendix 1. Scoring criteria for semantic knowledge

\begin{tabular}{|c|c|c|c|c|}
\hline & & 상위어 & 구조적 특징 & 기능적 특징 \\
\hline 1 & 바지 & 옷 & $\begin{array}{l}\text { 길이와 모양이 다양하다 } \\
\text { 단추와 지퍼가 달려있다 }\end{array}$ & $\begin{array}{c}\text { 몸을 가릴 수 있다(몸을 보호할 수 있다) } \\
\text { 입는다 }\end{array}$ \\
\hline 2 & 자동차 & 교통 수단 & $\begin{array}{c}\text { 바퀴가 있다 } \\
\text { 모양과 크기가 다양하다 }\end{array}$ & 사람이나 짐을 실을 수 있다 \\
\hline 3 & 의자 & 가구 & $\begin{array}{c}\text { 나무나 금속(철제)로 만들어진다 } \\
\text { 등받이가 있다 } \\
\text { 다리가 있다 }\end{array}$ & 앉을 수 있다 \\
\hline 4 & 텔레비전 & 전자제품 & $\begin{array}{l}\text { 네모나다 } \\
\text { 화면이 있다 }\end{array}$ & 방송을 볼 수 있다 \\
\hline 5 & 사과 & 과일 & $\begin{array}{l}\text { 빨간색/초록색 } \\
\text { 달다, 시다 } \\
\text { 동그랗다 }\end{array}$ & $\begin{array}{c}\text { 주스나 잼으로 만들어 먹을 수 있다 } \\
\text { 칼로 깎아서 먹는다 }\end{array}$ \\
\hline 6 & 커피 & 음료 & $\begin{array}{l}\text { 갈색/검정색 } \\
\text { 쓰다 }\end{array}$ & 마실 수 있다 \\
\hline 7 & 호랑이 & (네발)동물 & $\begin{array}{l}\text { 노랑(주황, 갈색) } \\
\text { 검정 줄무늬가 있다 } \\
\text { 몸집이 크다 }\end{array}$ & $\begin{array}{c}\text { 산에 산다 } \\
\text { 다른 동물들을 잡아 먹는다 }\end{array}$ \\
\hline 8 & 귀 & $\begin{array}{l}\text { 신체 } \\
\text { 부위 }\end{array}$ & $\begin{array}{l}\text { 둥그렇다, 반달모양 } \\
\text { 말랑말랑하다 }\end{array}$ & $\begin{array}{c}\text { 소리를 듣는다 } \\
\text { 몸의 균형을 잡는다 }\end{array}$ \\
\hline 9 & 수박 & 과일 & $\begin{array}{c}\text { 씨가 있다 } \\
\text { 빨간색/초록색 } \\
\text { 줄무늬가 있다 } \\
\quad \text { 달다 }\end{array}$ & 먹을 수 있다 \\
\hline 10 & 까마귀 & 새 & $\begin{array}{c}\text { 검정색 } \\
\text { 날개가 있다 } \\
\text { 부리가 있다 }\end{array}$ & $\begin{array}{l}\text { 날 수 있다 } \\
\text { 알을 낳는다 }\end{array}$ \\
\hline 11 & 거미 & 곤충 & 다리가 많다 & $\begin{array}{c}\text { 기어 다닌다 } \\
\text { 실을 뿜어낸다 } \\
\text { 작은 곤충들을 먹는다 }\end{array}$ \\
\hline 12 & 비누 & 욕실용품 & $\begin{array}{c}\text { 미끄럽다 } \\
\text { 모양,색,향이 다양하다 }\end{array}$ & $\begin{array}{l}\text { 씻을 때 사용한다 } \\
\text { 거품이 난다 }\end{array}$ \\
\hline 13 & 피아노 & 악기 & 여러 개의 건반으로 이루어져 있다. & $\begin{array}{c}\text { (건반을) 치면 소리가 난다 } \\
\text { 연주한다 }\end{array}$ \\
\hline 14 & 연필 & 학용품 & $\begin{array}{l}\text { 뾰족하다 } \\
\text { 심이 있다 }\end{array}$ & 글씨를 쓸 때 사용한다 \\
\hline 15 & 주전자 & 주방용품 & $\begin{array}{c}\text { 금속재질로 만들어져 있다 } \\
\text { 뚜껑/주둥이가 있다 }\end{array}$ & $\begin{array}{l}\text { 물을 끓이는데 사용한다 } \\
\text { 물을 따르는데 사용한다 }\end{array}$ \\
\hline
\end{tabular}




\section{국문초록}

\section{파킨슨병 환자의 의미적 군집화 특성 및 관련 기제}

이선미 ${ }^{*}$ 윤지혜 ${ }^{*}$ 이수정 3

'한림대학교 보건과학대학원 언어병리학과, ${ }^{2}$ 한림대학교 언어청각학부, ${ }^{3}$ 대구카톨릭대학교 언어청각치료학과

배경 및 목적: 파킨슨병 환자는 범주유창성과제 수행 시 전환능력은 저하되지만 군집능력은 유지되는 것으로 보고된다. 범주유창성 과제와 같이 시간 제한이 있는 과제에서는 전환의 수가 많아지면 군집의 수가 적어지고 군집의 수가 많아지면 전환의 수는 적어질 수 있 다. 본 연구는 파킨슨병 환자들을 대상으로 시간 제한 여부에 따라 범주유창성과제에서의 군집능력이 어떻게 달라지는지를 확인하였 다. 또한 위계가 있는 의미지식과제를 시행하여 군집능력의 근간을 이루는 의미지식 특성을 살펴보고 군집능력과 의미지식 간의 관계 를 확인하였다. 방법: 파킨슨병 환자 27 명과 정상인 32 명을 대상으로 시간 제한 여부에 따른 범주유창성과제의 군집과 전환 양상을 측 정하였다. 또한 의미지식과제(스스로 정의하기, 유도질문에 답하기, 선택질문에 답하기)의 수행력을 분석하였다. 결과: 첫째, 시간 제한 이 없는 경우 파킨슨병 환자군이 정상군에 비해 평균군집크기가 저하되었으며, 시간 제한이 있는 경우 두 집단 간 차이가 나타나지 않 았다. 둘째, 의미지식과제의 총점 및 유도질문 답하기는 파킨슨병 환자군이 정상군에 비해 저하되었다. 셋째, 파킨슨병 환자군의 군집 능력은 의미지식과제와 유의한 상관을 보였다. 논의 및 결론: 본 연구는 범주유창성 과제의 시간 제한 여부가 파킨슨병 환자의 군집 능 력에 영향을 미칠 수 있으며, 파킨슨병 환자의 군집 능력 저하는 의미지식 자체의 결함에 기인한다기보다 의미지식을 적절히 인출하는 단계에서의 결함을 반영한다는 사실을 시사한다.

핵심어: 파킨슨병, 범주유창성과제, 군집, 전환, 의미지식

본 논문은 2017년도 한림대학교 교비연구비에 의하여 연구되었음(No. HRF-201712-006).

\section{참고문헌}

강연욱(2006). K-MMSE (Korean-Mini Mental State Examination)의 노인 규준 연구. 한국심리학회지: 일반, 25, 1-12.

강연욱, 진주희, 나덕렬, 이정희, 박재설(2000). 통제 단어 연상 검사 (Controlled Oral Word Association Test) 의 노인 규준 연구. 한국심리학회지: 임

상, $19,385-392$

기백석(1996). 한국판 노인 우울 척도 단축형의 표준화 예비연구. 신경정신의학, 35, 298-307.

김수정, 최현주(2012). 노년층의 명사 정의하기 특성. 언어청각장애연구, 17, 107-117.

김예슬, 윤지혜(2016). 노화에 따른 명사, 동사, 형용사 정의하기 특성. 언어청각장애연구, 21, 271-283.

김정완, 강연욱, 윤지혜(2015). 55-74세 성인의 명사 범주 규준조사. 언어청각장애연구, 20, 559-569.

김지연(2016). 장·노년층의 생성이름대기 영향 요인:작업기억, 집행기능, 교육년수를 중심으로. 연세대학교 대학원 석사학위논문.

사수연, 최진영, 석정서(2011). 범주유창성 과제로 평가한 한국 노인들의 의미지식 구조. 한국심리학회지: 일반, 30, 227-242.

서상규(2014). 한국어 기본어휘 의미빈도 사전. 서울: 한국문화사.

성지은, 김진경(2011). 청년층과 노년층간 생성이름대기에서 나타난 범주별 전형성 비교: 의미복잡성 이론에 근거한 이름대기 치료 프로토콜 개발 예

비 연구. 언어치료연구, 20,31-49. 